\title{
An Assessment of Disparities in Diversity of Crop at Block Level in West Bengal
}

\section{Rukhsana*}

Assistant Professor, Department of Geography, Aliah University, Kolkata, India

*Corresponding Author: Rukhsana, Assistant Professor, Department of Geography, Aliah University, Kolkata, India.
Received: September 17, 2021

Published: November 10, 2021

(C) All rights are reserved by Rukhsana.

\begin{abstract}
Agricultural diversity can be described as a move from regional dominance of one crop towards the production of a large number of crops to meet the growing demand for those crops. This paper examines the crop diversification at district and sample block level in West Bengal, a state in the eastern region of India. The areas of crop diversification (Herfindahl index) have been developed to detect diverse agricultural impacts in West Bengal. Some districts in West Bengal have been cited as effective traditional systems of farming, lack of technology, average holding size and low diversification of per capita income. The expansion of crop diversification depends on improvement in production risk through technical assistance, quality input supply, insurance cover and the existence of modern storage-processing centers in the region. The study results show that West Bengal's agricultural sector is gradually moving towards higher value items.
\end{abstract}

Keywords: Crop Diversification; Herfindalh Index; District; Block

\section{Introduction}

In the current scenario for policy makers and researchers, crop diversification is an important issue of discussion as they relate diversification with growth prospects. It is said that the concept of crop diversification is the opposite of crop adjectives. Farmers around the world, especially in developing countries, try to cultivate several crops in their catch in a given year. Performance of crop diversification mostly depends on the socioeconomic, technological development and geo-climate conditions in any region. It is generally known that increasing agricultural technology is reaching a degree of decreasing crop diversification. Poor and marginal farmers mostly intend to diversify agriculture compared to rich farmers who like to specialize in crops $[2,11]$. The term 'diversification' is taken from the term 'diverge', which means to grow or move in a different type of direction from a common point
[4]. Diversified agriculture can be defined as a shift from regional dominance of a crop towards large number of crops production to meet the growing demand for those crops. A diverse agricultural economy opens up many opportunities such that soil fertility can be increased through crop rotation. It adds value to agriculture by increasing total crop productivity as well as stabilizing agricultural income by reducing risk related to only one crop. Studies have shown that farmers in India own small lands and their agricultural income and non-agricultural income are not sufficient to meet their subsistence level. Whereas on the other hand, countries that cultivate only certain crops are more risky due to fluctuations in domestic and international prices, therefore, both horizontal and vertical variations become the need of the hour. The movement of low-value agriculture to high value agriculture includes crop diver-

Citation: Rukhsana. “An Assessment of Disparities in Diversity of Crop at Block Level in West Bengal". Acta Scientific Agriculture 5.12 (2021): 03-09. 
sification pilots that increase agricultural production. Crop diversification has become an important option in developing countries to achieve the objectives of production growth, employment generation and sustainability of natural resources [8]. Crop diversification is necessary for an agro-based economy. Over the years, practices known to farmers have forced them to diversify agricultural activities to meet their families' cash needs and water tables, reducing floods and droughts, climate change and net sown to reduce risks such as reducing the area [10]. This study is to examine the nature of the variation in the crop diversification at the district level in West Bengal, and find out the variation of crop diversification at micro level including selected blocks level.

\section{Data base and methodology and study area}

The West Bengal, state lies between 21ํㅜㄴ' and 27 is13'14" north latitude and 85 located 45'20" and 89 long 53' east longitude. West Bengal is organized into 66 sub-divisions and 341 develop- ment blocks in 19 districts. It is a state in the eastern region of India with a wide variety of physical diversities and shares international borders with Bangladesh and Nepal. Since the pre-independence period in West Bengal, the variation in crop pattern is a very recent phenomenon apart from the tea case of the crop harvest. Rice is a dominating crop in West which achieved at a very high productivity in paddy cultivation during the eighties and nineties. Crop diversification considered as a way to increase the contribution to the production ratio of non-rice crops in order to found the higher agricultural growth rates in the future. Apart from boosting development, it is felt that diversification can also contribute to higher nutrition levels, poverty alleviation, employment generation and sustainable natural resource management.

The present study is based on secondary data, collected from various issues of the Statistical Abstract and Economic Review of West Bengal, published by the Bureau of Applied Economics and

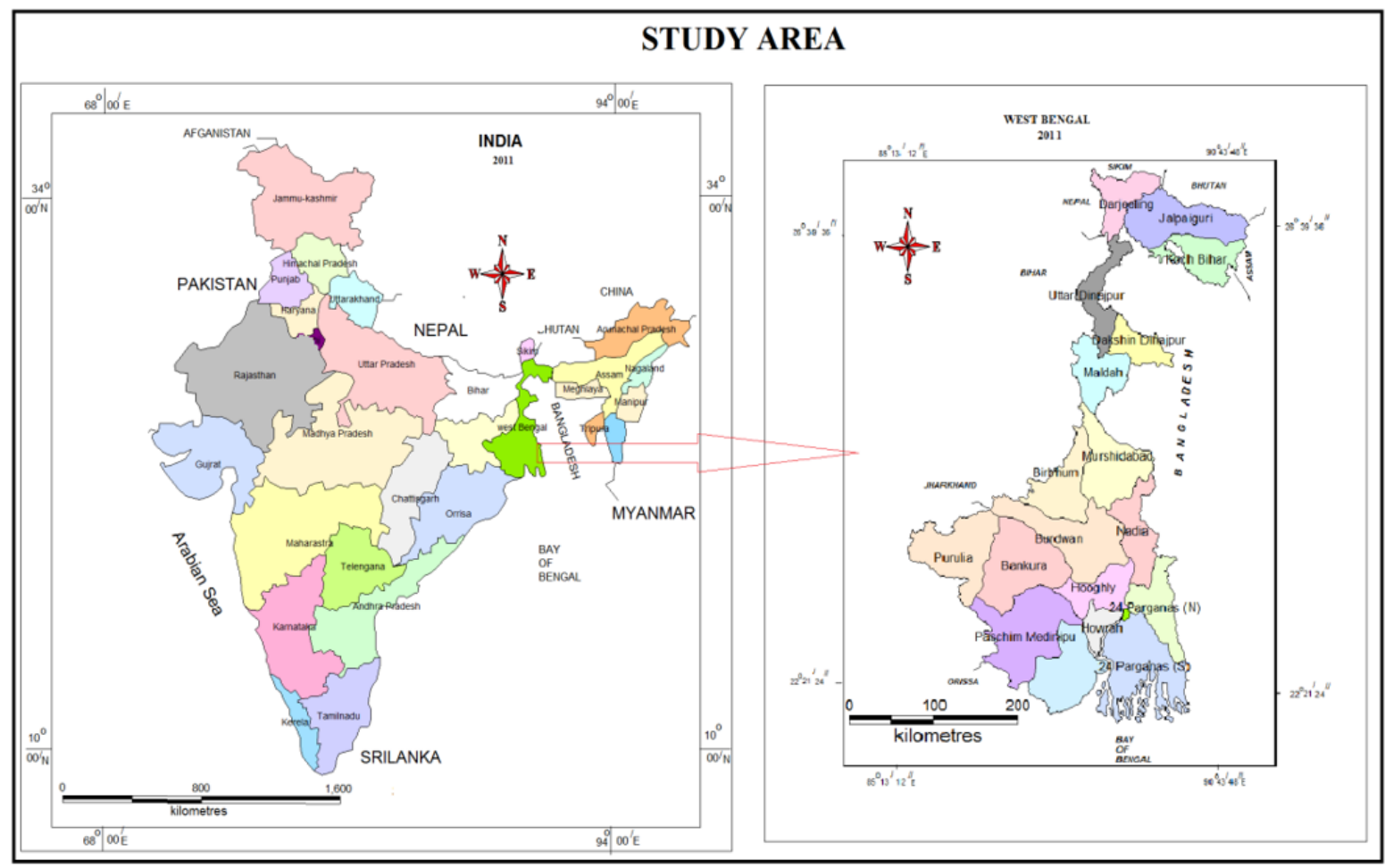

Figure 1

Citation: Rukhsana. "An Assessment of Disparities in Diversity of Crop at Block Level in West Bengal". Acta Scientific Agriculture 5.12 (2021): $03-09$. 
Statistics, Government of West Bengal, for the time periods of 2012-13. There are various methods for studying the extent of diversification which are available in the literature. There are several statistical methods that measured the magnitude of variation, including maximum ratios, Simpson index, entropy index, modified entropy index, composite entropy index, augive index, and Heridenhal - Herschmann index, etc. Kumar., et al. 2012 [6], Benin., et al. 2004 [1], Chand 1996 [3] and Pandey and Sharma 1996 [7] have used these index in their work. Each of these tools has its own advantages and limitations of data requirement and ease of calculation and interpretation. Additionally, results obtained through these methods are more or less the same.

Crop diversification (CDI) index has been calculated in determining crop diversification for particular crops of interest. The CDI is obtained by subtracting the Herfindalh Index (HI) from one. CDI is an index of concentration and has a direct relationship with diversification where a zero value represents specialization and greater than zero indicated crop diversification. Thus, it becomes easier to identify farmers who are practicing crop diversification. The Heritage Index formula has been applied to refine the crop diversification area in the study area. Herfindalh Index given below is computed by taking sum of squares of acreage proportion of each crop in the total cropped area. Mathematically, the index is given as below.

Herfindalh Index $(\mathrm{HI})=\sum_{\mathrm{i}-1}^{\mathrm{N}} \mathrm{P}_{\mathrm{i}}^{2}$

Where $\mathrm{N}$ represents the total number of crops and $\mathrm{Pi}$ is area proportion of the i-th crop in total cropped area. With the increase in diversification, the Herfindalh Index would decrease. This index takes a value one when there is complete concentration and approaches zero when diversification is perfect. Thus the Herfindalh Index is bounded by Zero and one.

\section{Result and Discussion}

District wise analysis of Crops Diversification in West Bengal during 2012-13: Based on the Harfendal Index of crop diversification, West Bengal mainly divided into five categories (Very High, High, Medium, Low and Very Low). Table 1 and figure 2 (A) depicts that the present scenario of crop diversification in west Bengal during 2012-13. The sample mean of the Herfindahl index is 0.057 which counted as the highest Herfindalh index IN West Bengal. Conversely crop diversification mainly occurs in northern regions of West Bengal. Table 1 portrayed that the districts namely Howrah is the very highest diversified district followed by Dakshin Dinajpur (0.01), Birbhum (0.01) and Cooch Behar (0.01). While highest diversification reported in eight districts namely South 24 Parganas (0.03), North 24 Parganas (0.02), Bankura (0.02), Jalpaiguri (0.03), Uttar Dinajpur (0.02), Maldah (0.03), Murshidabad (0.0.3) and Darjeeling (0.04) in term of agricultural practices during 2012-13. Therefore, it observed that districts like Birbhum along with Uttar Dinajpur have made tremendous improvement in terms of crops diversification during said period in the State of West Bengal. The moderate diversification has been noticed in the districts of Hoogly (0.08), Burdwan (0.08) and Purba Mednipur (0.08). These districts have made significant improvement in agriculture field in general and crops diversification in particular during 2012-13 it due to improvement of irrigation facilities and changes in institutional holding size and accessibility to market.

\begin{tabular}{|c|c|c|}
\hline Sl. No. & Name of the District & 2012-13 \\
\hline 1 & Burdwan & 0.06 \\
\hline 2 & Ccooch Behar & 0.01 \\
\hline 3 & South 24 Parganas & 0.03 \\
\hline 4 & North 24 Parganas & 0.02 \\
\hline 5 & Bankura & 0.02 \\
\hline 6 & Dakshin Dinajpur & 0.01 \\
\hline 7 & Darjeeling & 0.04 \\
\hline 8 & Hawrah & 0.00 \\
\hline 9 & Maldah & 0.03 \\
\hline 10 & Hoogly & 0.08 \\
\hline 11 & Jalpaiguri & 0.03 \\
\hline 12 & Murshidabad & 0.03 \\
\hline 13 & Nadia & 0.25 \\
\hline 14 & Paschim Mednipur & 0.17 \\
\hline 15 & Purba Mednipur & 0.08 \\
\hline 16 & Uttar Dinajpur & 0.02 \\
\hline 17 & Purulia & 0.13 \\
\hline 18 & Birbhum & 0.01 \\
\hline Total Average & & 0.057 \\
\hline
\end{tabular}

Table 1: Extent of Crops Diversity in West Bengal at district level.

Source: Compiled by Author after collected data from, Statistical Handbook West Bengal (2012), Bureau of Applied Economics \& Statistics Department, Kolkata, West Bengal (2012). 

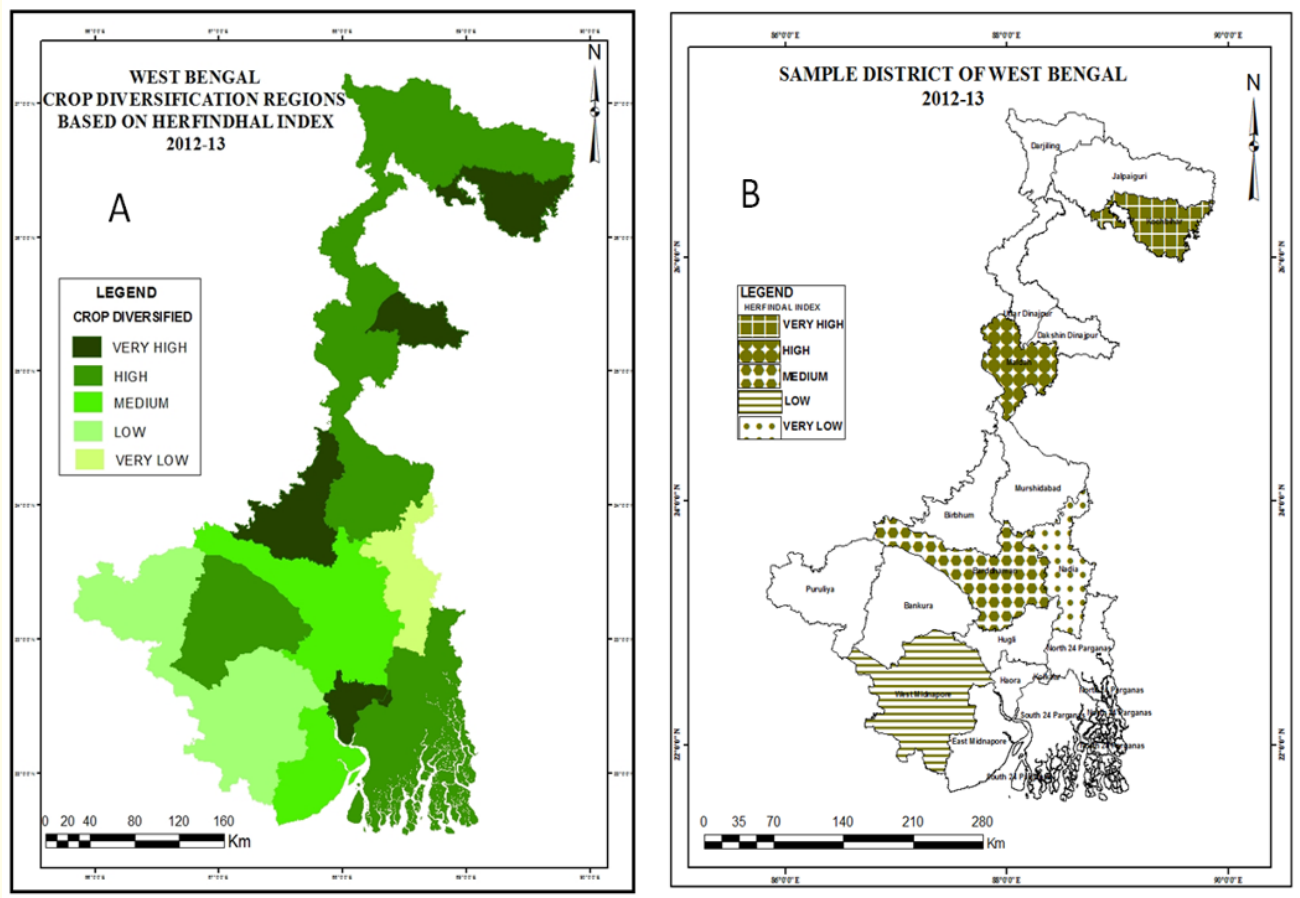

Figure 2

Based on the Harfendal Index of crop diversification, whole West Bengal mainly divided into five categories (Very High, High, Medium, Low and Very Low). Five sample districts has been selected (one from each category of West Bengal crop diversification region, Figure 2 A) for block wise analysis of crop diversification to know the micro level variation of crop diversity at block level which includes Cooch Behar, Malda, Bardhaman, Nadia and Paschim Medinipur districts (Figure 2 (B)).

\section{Block wise analysis of crop diversification in sample district \\ Cooch behar district}

Figure 3 (A) demonstrate block wise distribution of crop diversification regions based on Herfindhal index. Same figure shows that only two blocks has been found under very high crop diversification which include Cooch Behar-I (0.42) and Tufanganj-I (0.41). The said blocks are dominated by various types of crops which has been able to grown in this region with favorable soil condition. On the other hand high crop diversification has been recorded in two blocks namely Tufanganj-II (047) Dinhata-II (0.46) and two found under medium diversification block like Dinhata-I (0.51) and Mathabhanga-II (0.51) in terms of agriculture practice. Low diversified block includes Tufanganj-II (0.57), Cooch Behar-II (0.55), Mathabhanga-I (0.58), Mekhliganj (0.58) in terms of agriculture practice. Sitai (0.63) and Haldibari (0.6) block comes under very low diversification of crop in Cooch Behar district.

\section{Malda district}

Figure 3 (B) demonstrate block wise distribution of crop diversification of Malda district based on Herfindhal index from which it has been observed that very high crop diversification found in to two block only like Kalichak-III (0.2) and Kaliachak-II (0.2). High crop diversification has been registered in to Kaliachak-I (0.27), English Bazar (0.28), Manikchak (0.29), Ratua-II (0.27), and Ratua-I (0.29) blocks. Medium diversification found in to two blocks only including Harishchandrapur-I (0.38), and HarishchandrapurII (0.48). While low diversification has been observed in to four blocks including Malda Bazar (old) (0.59), Gazol (0.58), Chanchal_ 


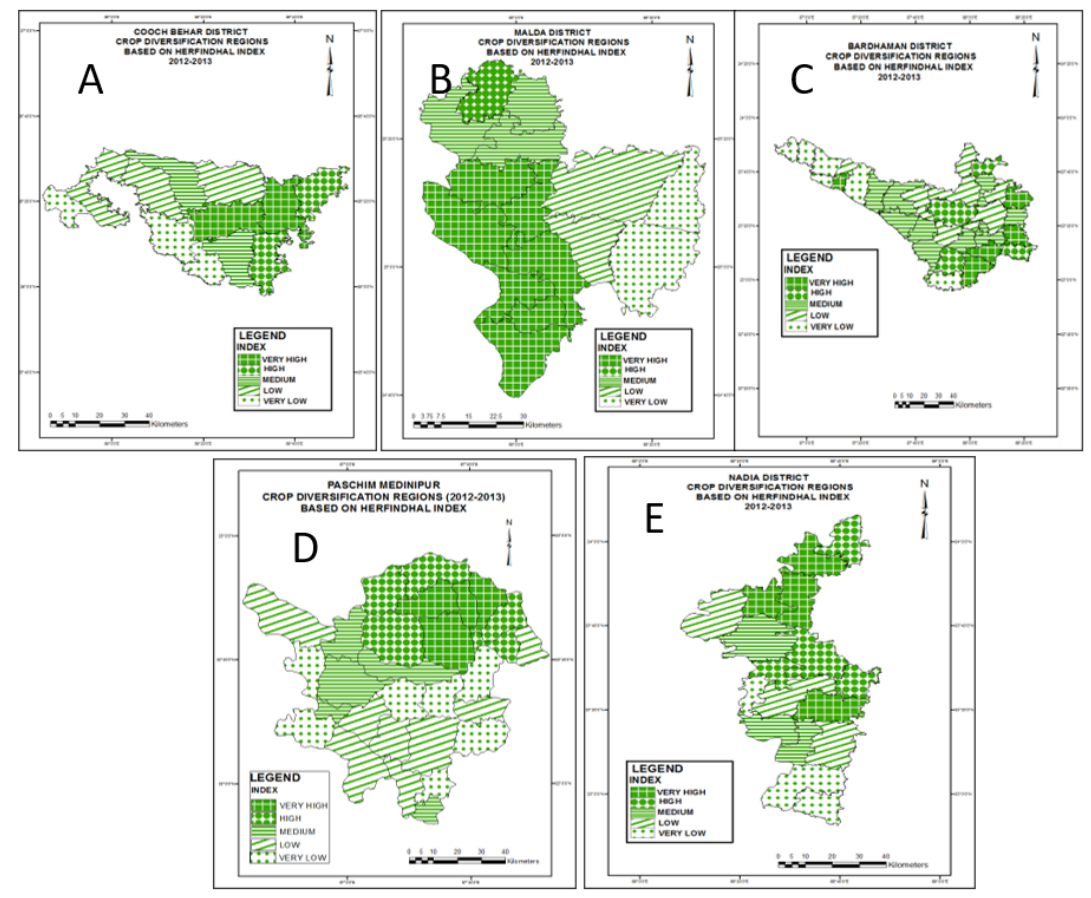

Figure 3: Based on data in appendix 1.

II (0.54), and Chanchal-I (0.49), on the other hand very low diversified block like Habibpur (0.76) and Bamangola (0.67).

\section{Bardhhaman district}

Figure 3 (C) shows that the very high crop diversification has been found into five blocks including Jamalpur (0.51), MemariI (0.58), Kalna-I (0.53), Ondal (0.52) and Purbhasthali-II (0.48) which has been highly dominated by various types of crops because the region are covered by fertile sedimentary soil which is favorable for cultivation. High crop diversification found in to three blocks only which contain Raina-I (0.72), Bhatar (0.72), and Ketugram-II (0.72). Nine blocks come under medium diversification in terms of agriculture while low has been reported in to seven blocks. On the other hand very low crop diversification found in Raina-II (1.00), Faridpur-Durgapu (0.99), Barabani (1.00), and Salanpur (1.00).

\section{Paschim medinipur district}

Figure 3 (D) explained that the very high crop diversification observed in four blocks namely Garbeta-III (0.359), Chandracona-
I (0.410), Chandrocona-II (0.361) and Keshpur (0.367). The said blocks are dominated by various types of crops which has been able to grown in this region with favorable soil condition. On the other hand high diversified block recorded in Salboni (0.567), keshpur (0.474), Garbeta-I) 0.570), Garbeta-II (0.518) Ghatal (0.541), Dashpur-I (0.618) in terms of agriculture practice. While medium diversification in crop found Jhargram (0.759), Binpur-I (0.746), Gopiballavpur-II (0.730), Medinipur (0.731), and Mohanpur (0.711) and low diversification has recorded into seven blocks. Rest block lie under very low diversification in terms of agriculture.

\section{Nadia district}

Figure 3 (E) identified that the very high crop diversification has been registered into four blocks including Hanskhali (0.221), Tehatta-II (0.214), Tehatta-I (0.204), Karimpur-II (0.205) which has been highly dominated by various types of crops because the region are covered by fertile sedimentary soil which is favorable for cultivation. High crop diversification has been observed into four block including Krishnaganj (0.234), Krishnagar-II (0.243), 
Chapra (0.250) and Karimpur-I (0.237) in terms of agriculture practice. Only three block namely Ranaghat-I (0.288), Santipur (0.282), nakshipara (0.266) lie under medium diversification in terms of agriculture practice. On the other hand low diversified block composed to Ranaghat-0.309), Krishnagar-I (0.322) and Kaliaganj (0.314) and very low diversification of crops found in Haringhata (0.384), Chakdah (0.375) and Nabadwip (0.429).

\section{Conclusion}

The study shows that the northern parts of West Bengal such as Darjeeling, Jalpaiguri, Cooch Behar, Dakhin Dinajpur, Uttar Dinajpur, Burdwan and Malda etc. have made tremendous progress in the period of crop diversity in the state of West Bengal during the study period. Cooch Behar district, which is counted for much diversification in terms of agriculture due to the population of the district, is dominated only by agribusiness. Agriculture is very developed in Cooch Behar district; Most of the 80-90 percent population here is engaged in agriculture. Therefore, it has been safely declared that, most of the districts and blocks of West Bengal are trying to move towards diversification of crops and some of them have made significant progress in this area and some are trying to do the same. At the same time, there are also districts in the state of West Bengal that are trying to advance along with crop specialization. However, there is spatial variation in crop concentration which is the result of various physiological, hydrological, pedological and socio-economic factors in West Bengal. The results of the study show that West Bengal's agricultural sector at block level is gradually moving towards high value commodities. It is ascertained that most of the diversification comes with little support from the government through individual efforts of small farms. The reason for this is that the issues of food security in the state as well as in the country are still serious and the government policy is still selfsufficient in terms of food grains. Also the degree of diversification is not evenly distributed across districts and sample block. While some blocks are increasingly picking up diversification, others are lagging far behind. This may be due to the fact that even though the state has achieved self-sufficiency in staple food, the emphasis is still focused on increasing rice production.

\section{Acknowledgement}

I am sincerely indebted to Indian Council of Social Science Research (Ministry of Human Resource) Development, New Delhi, 110067, India, for sponsored me Major Research Project.
Bibliography

1. Benin S., et al. "The economic determinants of cereal crop diversity on farm in Ethiopian highlands". Agricultural Economics 3 (2004): 197-208.

2. Birthal P S and N M. "Sources of Agricultural Growth in India: Role of Diversification towards High Value Crops, New Delhi: Markets". Trade and Institutions Division, IFPRI (2007).

3. Chand R. "Diversification through High Value Crops in Western Himalayan Region: Evidence from Himachal Pradesh". Indian Journal of Agricultural Economics 41.4 (1996): 652-663.

4. Jha, Kumar and Mohanty. "Growth and Instability in Agriculture Associated with New Technology: District Level Evidences". Agricultural Situation in India 49.4 (2000): 517-524.

5. Joshi P K and A G. "From Plate to Plough: Agricultural Diversification in India" (2003): 25-26.

6. Kumar Anjani., et al. "Crop Diversification in Eastern India: Status and Determinants". Indian Journal of Agricultural Economics LXVII.4 (2012): 600-616.

7. Pandey V K and Sharma K C. "Crop diversification and self-sufficiency in food grains". Indian Journal of Agricultural Economics LI.4 (1996): 644-651.

8. Petit M and Barghouti S. "Diversification: Challenges and opportunities". In: Trends in Agricultural Diversification: Regional Perspectives, In L. G. Shawki Barghouti, World Bank Technical Paper Number. Washington D.C (1992).

9. Radhakrishna R. "Food and Nutrition Security of Poor: Emerging Perspectives and Policy Issues". 40.18 (2005): 1817-1823.

10. Sinha D K and Ahmad Nasim S K. "Shrinking net sown area: An analysis of changing land use pattern in Bihar". Journal of Agrisearch 3.4 (2016): 238-243.

11. Swati G., et al. "Factors influencing crop diversification as Tool to two fold farmers' earnings in Uttarakhand". Indian Journal of Economics and Development 13.2 (2017): 228-233.

12. Tao F., et al. "Global warming, rice production, and water use in China: developing a probabilistic assessment". Agricultural and Forest Meteorology 148.1 (2008): 94-110. 
13. Tiemann LK., et al. "Crop rotational diversity enhances belowground communities and functions in an agro ecosystem". Ecology Letter 18.8 (2015): 761-771.

14. Vyas S V. "Diversification of Agriculture: Concept, Rationale and approaches". Indian Journal of Agricultural Economics 51.4 (1996): 636-646.

Volume 5 Issue 12 December 2021

(c) All rights are reserved by Rukhsana. 